\title{
Analysis of the Talbot effect in apodized diffractive optical elements
}

\author{
Tomasz Osuch, ${ }^{* 1}$ and Zbigniew Jaroszewicz ${ }^{1,2}$ \\ ${ }^{I}$ National Institute of Telecommunications, Szachowa 1, 04-894 Warsaw, Poland \\ ${ }^{2}$ Institute of Applied Optics, Kamionkowska 18, 03-805 Warsaw, Poland
}

Received November 18, 2009; accepted December 29; 2009; published December 31; 2009

\begin{abstract}
This paper shows numerical results of the Talbot effect appearing behind an apodized phase mask. The field distributions in the self-image plane as well as in other characteristic planes are examined drawing on scalar diffraction theory and modified convolution approach. Simulation results show interesting properties of field distributions behind diffractive optical element with variable phase step height. The novelty of the article lies in examination of the self-image phenomenon in fibre Bragg gratings fabrication.
\end{abstract}

The self-image (or Talbot) effect was discovered by H.F. Talbot in 1836 [1] and explained by Lord Rayleigh fifty years later [2]. When a plane wave is illuminating a periodic object, its replicas appear behind the structure in characteristic distances $\mathrm{z}=\mathrm{v} \cdot \mathrm{z}_{\mathrm{T}}, \mathrm{v}-$ integer and $\mathrm{z}_{\mathrm{T}}$ denotes the self-image distance (Talbot length):

$$
z_{T}=\frac{2 d^{2}}{\lambda}
$$

where $d$ is the period of the structure and $\lambda$ stands for the used wavelength. Until now, the self-image effect has been extensively analyzed both theoretically and experimentally [3-7].

Assuming the illumination of phase grating by monochromatic light, some interesting properties of Fresnel images were observed [8], [9]. For example, in planes $\mathrm{z}=\mathrm{V} \cdot \mathrm{Z}_{\mathrm{T}} / 2$ the intensity distribution in $\mathrm{x}$-axis (parallel to the grating) is constant $I\left(x, \quad z=\mathrm{V} \cdot \mathrm{z}_{\mathrm{T}} / 2\right)=1$. Moreover, the longitudinal symmetry around $\mathrm{z}_{\mathrm{T}} / 2$ with a shift of $\mathrm{d} / 2$ exists in field distribution behind the illuminated grating, according to the following formula $I(x, z)=I\left(x+\mathrm{d} / 2, \quad z+z_{\mathrm{T}} / 2\right)$. For binary phase grating in planes $\mathrm{z}=(\mathrm{v}+1 / 4) \cdot \mathrm{z}_{\mathrm{T}}$ and $\mathrm{z}=(\mathrm{v}+3 / 4) \cdot \mathrm{z}_{\mathrm{T}}$ the binary intensity pattern appears and its modulation depends on the grating's phase step height $\varphi(x)$, i.e. $I\left(x, z=(\mathrm{v}+\mathrm{k} / 4) \cdot \mathrm{z}_{\mathrm{T}}\right)=1+\sin (\varphi), \mathrm{k}=1,3,5,7$. The visibility in these planes is described by

$$
\mathrm{V}=\frac{\mathrm{I}_{\mathrm{MAX}}-\mathrm{I}_{\mathrm{MIN}}}{\mathrm{I}_{\mathrm{MAX}}+\mathrm{I}_{\mathrm{MIN}}}=\sin (\varphi)
$$

In turn, in the planes $\mathrm{z}=(\mathrm{v}+\mathrm{k} / 8) \cdot \mathrm{z}_{\mathrm{T}}$, the appearing binary intensity pattern obeys the following formula [10]

\footnotetext{
*E-mail: T.Osuch@itl.waw.pl
}

$$
V=\frac{\sin (\varphi)}{\sqrt{2}}
$$

In this paper, the intensity distribution behind an apodized phase mask for fibre Bragg gratings (FBG) fabrication is examined [11],[12]. Generally, in optics apodization is used for changing the intensity distribution. Here, "apodization" term is related to the changing of the intensities in particular diffraction orders. In this case an apodized phase mask consists of different subsections (phase gratings with various phase step heights), which are stitched together. In this way, the phase mask with a staircase profile is obtained, because of technological limitations in DOE fabrication process (for example electron beam lithography).

In our simulations an incident plane wave with $\lambda=244 \mathrm{~nm}$ was assumed (double frequency of argon ion laser, which is commonly used for fiber Bragg gratings inscription). In order to obtain the Bragg wavelength of FBG within the third telecommunication window, we chose phase mask period $\mathrm{d}=1.06 \mu \mathrm{m}[13]$.

Intensity distributions were calculated using scalar diffraction theory [14], and modified convolution approach [15], [16]. Additionally, the illumination was assumed to be perfectly coherent. In Figures 1-4 there are presented field distributions behind various sections of the apodized phase mask with phase step heights $\pi, 3 \pi / 4$, $\pi / 2$ and $\pi / 8$, respectively.

In Fig. 1a, the $d / 2$ shift in symmetry around $z_{T} / 2$ is not noticeable, because the interference pattern's periodicity in $\mathrm{x}$-axis is half the period of the phase mask. Constant intensity distributions in planes $\mathrm{z}=(\mathrm{v}+1 / 4) \cdot \mathrm{z}_{\mathrm{T}}$ and $\mathrm{z}=(\mathrm{v}+3 / 4) \cdot \mathrm{z}_{\mathrm{T}}$ result from the phase shift $\varphi=\pi$ and therefore null visibilities are noticeable. In addition, according to equation (3), $\mathrm{V}=0$ in planes $\mathrm{z}=\mathrm{k} \cdot \mathrm{z}_{\mathrm{T}} / 8$. We also noticed symmetries around $\mathrm{z}=\mathrm{q} \cdot \mathrm{z}_{\mathrm{T}} / 16$ (Fig. 1c), for $\mathrm{q}=1,3, \ldots, 15$ and $\mathrm{z}=\mathrm{k} \cdot \mathrm{z}_{\mathrm{T}} / 8$ (fig. $1 \mathrm{~b}$ ). Summing up the above properties of the interference pattern for phase mask section with $\varphi=\pi$, it can be seen that the fundamental period of field intensity is $\mathrm{z}_{\mathrm{T}} / 8$ (the bottom graphics of the Fig. 1a).

Figures $2 \mathrm{a}-4 \mathrm{a}$ show that for $\varphi<\pi$, periodicity in $\mathrm{x}$-axis is equal to the phase mask period. This is an impact of the 
0 -th diffraction order. Its result is that, in comparison with the section with $\varphi=\pi$, the symmetries around $\mathrm{z}=\mathrm{k} \cdot \mathrm{z}_{\mathrm{T}} / 8, \mathrm{z}=\mathrm{q} \cdot \mathrm{z}_{\mathrm{T}} / 16$ cease to exist and $\mathrm{d} / 2$ shift at $\mathrm{z}=\mathrm{z}_{\mathrm{T}} / 2$ is more and more visible when the phase step height decreases.

In intensity distribution behind the analyzed apodized phase mask, the perturbations exist. They result from existence of phase jumps which come from stitching points of phase mask subsections with different phase step heights [17].

Figures 1-4 show intensity distributions behind the central parts of the phase mask sections, and thus
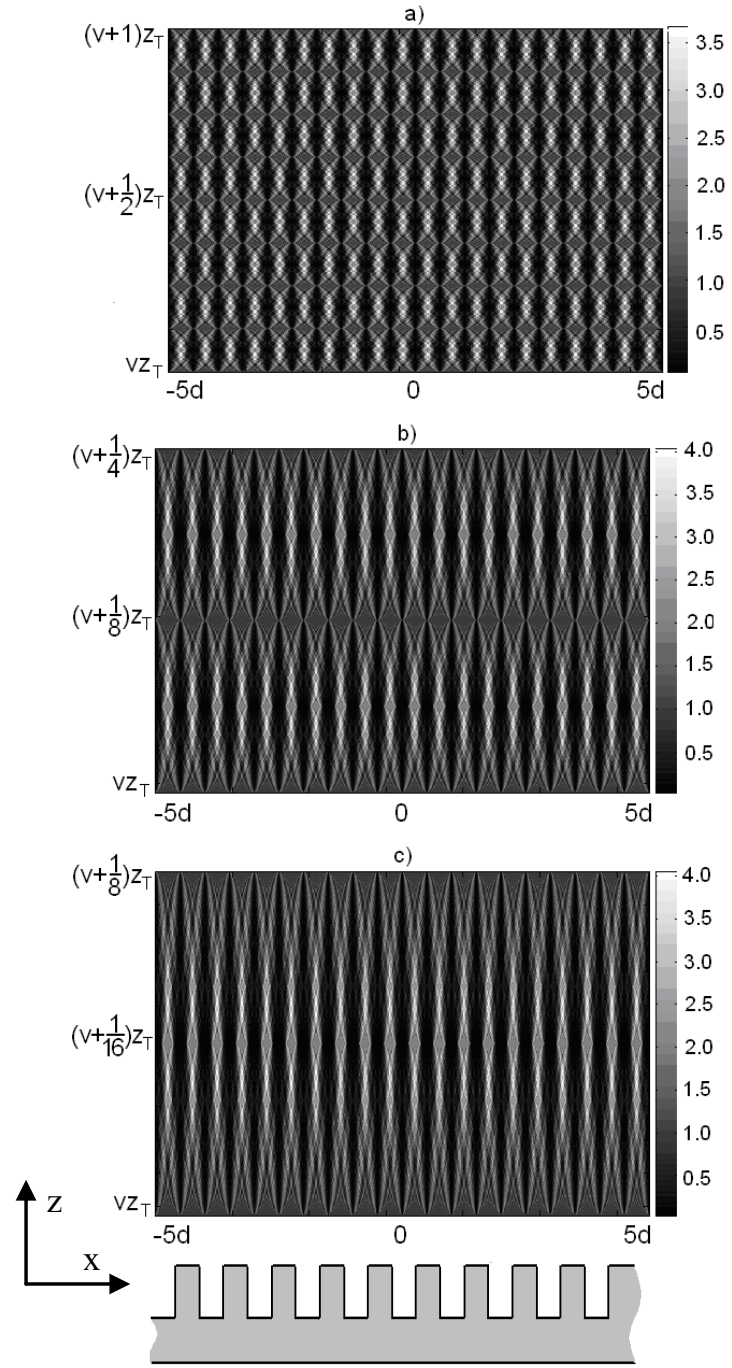

Fig. 1. Intensity distribution behind phase mask section with $\varphi=\pi$ in the range of: a) $\left\langle\mathrm{m} \cdot \mathrm{z}_{\mathrm{T}} ;(\mathrm{m}+1) \cdot \mathrm{z}_{\mathrm{T}}\right\rangle$, b) $\left\langle\mathrm{m} \cdot \mathrm{z}_{\mathrm{T}} ;(\mathrm{m}+1 / 4) \cdot \mathrm{z}_{\mathrm{T}}\right\rangle$ and $\left.\mathrm{c}\right)$ $\left\langle\mathrm{m} \cdot \mathrm{z}_{\mathrm{T}} ;(\mathrm{m}+1 / 8) \cdot \mathrm{z}_{\mathrm{T}}\right\rangle$.

perturbations are not noticeable in interference patterns. The whole phase mask, which consists of a few sections, also exhibits some interesting properties. Firstly, in planes $\mathrm{Z}=\mathrm{V} \cdot \mathrm{z}_{\mathrm{T}} / 2$ null visibility planes exist. Secondly, in planes $\mathrm{z}=(\mathrm{v}+1 / 4) \cdot \mathrm{z}_{\mathrm{T}}$ and $\mathrm{z}=(\mathrm{v}+3 / 4) \cdot \mathrm{z}_{\mathrm{T}}$ the visibility distributions exhibit a staircase function with the shape corresponding to the apodization profile of the phase mask. Therefore, it is possible to determine the phase step height profile of the phase mask with variable diffraction efficiency by means of Fresnel images measurement [18].

Presented here properties of intensity distribution behind the phase mask allow to assess the impact of optical fibre location on its quality during FBG fabrication. Due to the fact that the fundamental period of interference pattern in $\mathrm{x}$-axis behind the phase mask section with phase step height $\varphi=\pi$ (and therefore
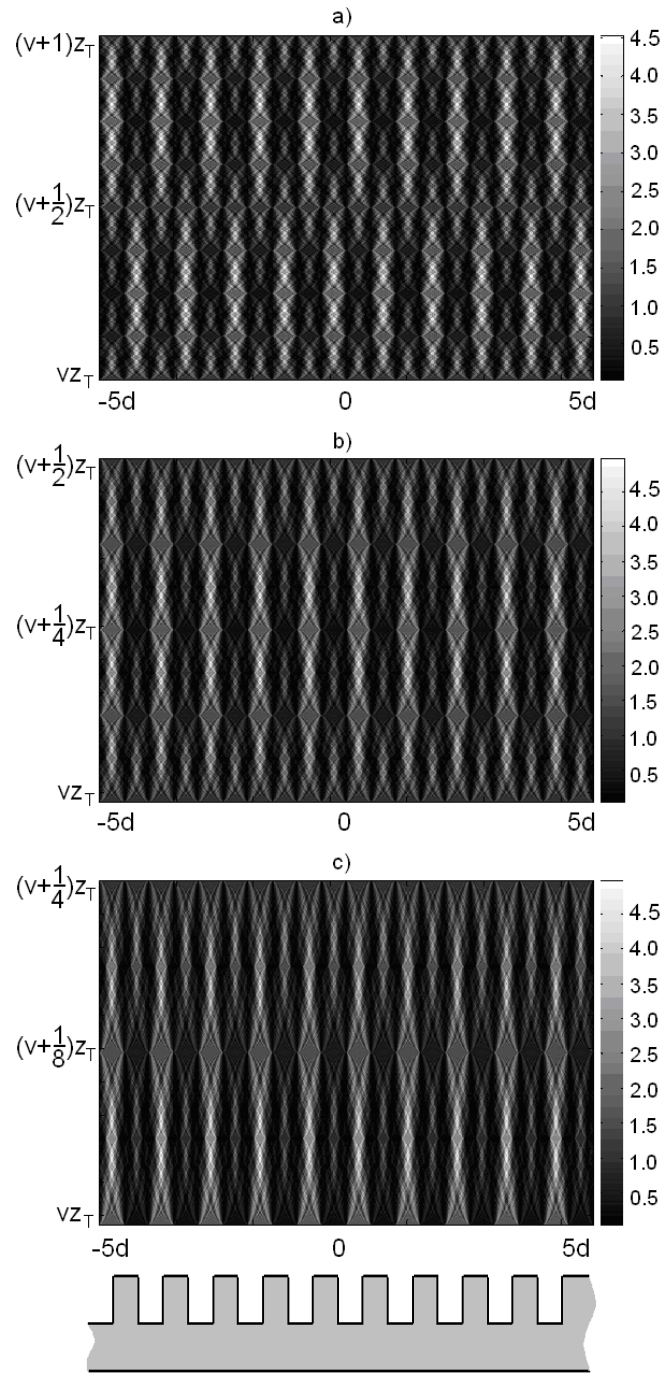

Fig. 2. Intensity distribution behind phase mask section with $\varphi=3 \pi / 4$ in the range of: a) $\left.\left\langle\mathrm{m} \cdot \mathrm{z}_{\mathrm{T}} ;(\mathrm{m}+1) \cdot \mathrm{z}_{\mathrm{T}}\right\rangle, \mathrm{b}\right)\left\langle\mathrm{m} \cdot \mathrm{z}_{\mathrm{T}} ;(\mathrm{m}+1 / 2) \cdot \mathrm{z}_{\mathrm{T}}\right\rangle$ and $\left.\mathrm{c}\right)$ $\left\langle\mathrm{m} \cdot \mathrm{z}_{\mathrm{T}} ;(\mathrm{m}+1 / 4) \cdot \mathrm{z}_{\mathrm{T}}\right\rangle$.

homogeneous phase mask) $\mathrm{Z}_{\mathrm{F}}=\mathrm{Z}_{\mathrm{T}} / 8$ is much smaller than the fibre core diameter $\mathrm{D}$, the impact of the position of the optical fibre on the average field intensity distribution in a fibre core is negligible.

In contrast, in the case of apodized phase mask where the 
phase step height $\varphi \in(0 ; \pi), \mathrm{D}$ is comparable with $\mathrm{Z}_{\mathrm{F}}=\mathrm{Z}_{\mathrm{T}}$, and thus the influence of fibre location on refractive index corrugation in a fibre core can be significant [19].
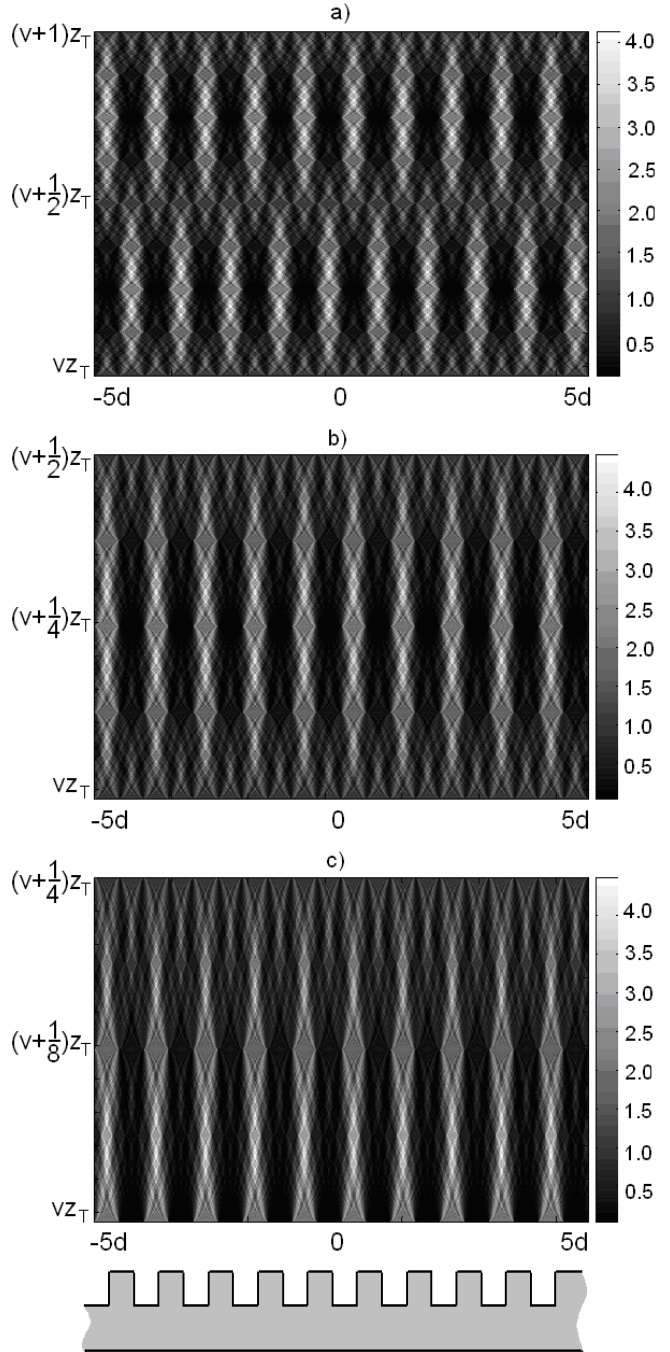

Fig. 3. Intensity distribution behind phase mask section with $\varphi=\pi / 2$ in the range of: a) $\left.\left\langle\mathrm{m} \cdot \mathrm{z}_{\mathrm{T}} ;(\mathrm{m}+1) \cdot \mathrm{z}_{\mathrm{T}}\right\rangle, \mathrm{b}\right)\left\langle\mathrm{m} \cdot \mathrm{z}_{\mathrm{T}} ;(\mathrm{m}+1 / 2) \cdot \mathrm{z}_{\mathrm{T}}\right\rangle$ and c) $\left\langle\mathrm{m} \cdot \mathrm{z}_{\mathrm{T}} ;(\mathrm{m}+1 / 4) \cdot \mathrm{z}_{\mathrm{T}}\right\rangle$.

\section{References}

[1] H. F. Talbot, Philos. Mag. 9, 401, (1836).

[2] L. Rayleigh, Philos. Mag. 11, 196 (1881).

[3] K. Patorski, The self-imaging phenomenon and its application, Progress in Optics 27, (North-Holland, Amsterdam, 1989).

[4] J. F. Barrera, R. Henao, Z. Jaroszewicz, A. Kołodziejczyk, Optik 116, 144 (2005).

[5] C. Gomez-Reino, M. T. Flores-Arias, M. V. Pérez, C. Bao, Opt. Commun. 183, 365 (2000)

[6] G. Shirripa Spagnolo, D. Ambrosini, Meas. Sci. Technol. 11, 77 (2000).

[7] A. W. Lohmann, J. A. Thomas, Appl. Opt. 29, 4337 (1990).

[8] V. Arrizon, J. Ojeda- Castaneda, JOSA 9, 1801, (1992).

[9] J. P. Guigay, Opt.Acta 18, 677 (1971).

[10] Z. Jaroszewicz, A. Kołodziejczyk, A. Kowalik, R. Restrepo, Optik 111, 207 (2000).
[11] J.Albert, K.O. Hill, B. Malo, S. Thériault, F. Bilodeau, D.C. Johnson, L.E. Erickson, Electron. Lett. 31, 222 (1995).
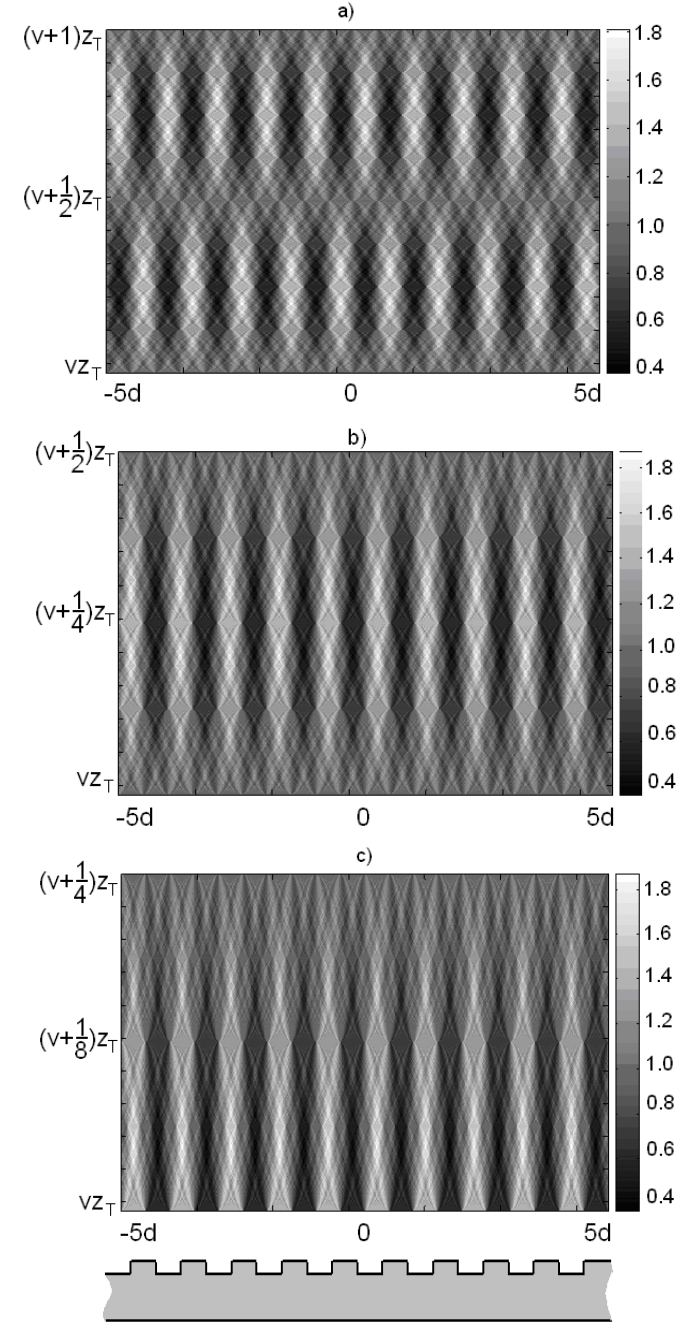

Fig. 4. Intensity distribution behind phase mask section with $\varphi=\pi / 8$ in the range of: a) $\left\langle\mathrm{m} \cdot \mathrm{z}_{\mathrm{T}} ;(\mathrm{m}+1) \cdot \mathrm{z}_{\mathrm{T}}\right\rangle$, b) $\left\langle\mathrm{m} \cdot \mathrm{z}_{\mathrm{T}} ;(\mathrm{m}+1 / 2) \cdot \mathrm{z}_{\mathrm{T}}\right\rangle$ and $\left.\mathrm{c}\right)$ $\left\langle\mathrm{m} \cdot \mathrm{z}_{\mathrm{T}} ;(\mathrm{m}+1 / 4) \cdot \mathrm{z}_{\mathrm{T}}\right\rangle$.

[12] B. Malo, S. Thériault, D.C. Johnson, F. Bilodeau, J. Albert, K.O. Hill, Electron. Lett. 31, 223 (1995).

[13] R. Kashyap, Fiber Bragg Gratings (Academic Press, 1999).

[14] J. W. Goldman, Introduction to Fourier optics (McGraw-Hill, New York, 1968).

[15] M. Sypek., Opt. Commun. 116, 43 (1995).

[16] M. Sypek, C. Prokopowicz, M. Górecki, Opt. Eng. 42, 3158 (2003).

[17] T. Osuch, Z. Jaroszewicz, A. Kołodziejczyk, Proc SPIE 6187, 61871, (2006).

[18] T. Osuch, Z. Jaroszewicz, A. Kowalik, EOS Topical Meeting on Diffractive Optics 2010, Koli, Finland, 14-18 February, (2010) accepted for publication.

[19] T. Osuch, Z. Jaroszewicz, EOS Topical Meeting on Diffractive Optics 2007, Barcelona, Spain 20-23 November, 212 (2007). 